\title{
Child growth (0-5 years), and the effect of entitlement to a milk supplement
}

\author{
P C ELWOOD, T J L HALEY, S J HUGHES, P M SWEETNAM, O P GRAY, AND D P DAVIES \\ MRC Epidemiology Unit (South Wales) and Department of Child Health, Welsh National School of Medicine, \\ Cardiff
}

SUMMARY Twelve hundred and fifty-one pregnant women were contacted and their infants followed to age 5 years. Nine hundred and fifty-one $(76 \%)$ children completed the trial. Measurements were made of birthweight, length, head circumference, and triceps skinfold at 10 days, and of weight, height, head circumference, and triceps skinfold at 5 years. Throughout the entire period of the study half the families, selected at random, were supplied with milk tokens entitling the mother, while pregnant, and all children under age 5 years, to 1 pint of milk a day at half its current price. The tokens led to a small increase in milk purchases by the families and to a small increase in milk drunk by the children. However no effect was detected in any growth measurement either in the total group, or in a more 'vulnerable' group of children from the largest families.

Attained height is a resultant of genetic, nutritional, and environmental factors. While nutrition is undoubtedly of great importance, it could be doubted if nutritional deprivation of a degree sufficient to affect growth occurs now in western countries. Yet the existence of social class differences in height in Great Britain ${ }^{1}$ and the lack of such differences in certain more affluent countries, such as Sweden, ${ }^{2}$ suggest that nutrition during growth is not adequate for all children in this country.

If growth is to be affected by a nutritional measure, it is likely that the earlier the intervention the greater the effect. Central and local government policy in the UK has acknowledged this, and while attention during the last 50 years has been given to improvements in the nutrition of schoolchildren, considerable efforts have also been made to secure the good nutrition of preschool children.

In 1940 legislation was enacted in the UK which made provision to every pregnant woman and every child up to age 5 years, of a pint of milk ( 20 fluid ounces or $568 \mathrm{ml}$ ) each day at half price (Welfare Food Act, 1940). Entitlement was effected by tokens which were acceptable to milk delivery firms. In 1971 this measure was greatly modified, and in effect withdrawn from all but the very poorest families.

In 1972 the opportunity was taken to set up a randomised controlled trial to investigate the effect on the growth of children, from early in pregnancy to 5 years, of entitlement to a daily supplement of milk comparable with that which had been available under the Welfare Food Act, 1940.

\section{Method}

The study was based on two small towns in South Wales, each of about 45000 total population. One is a seaside, industrial, residential town, with a social class distribution almost identical with that of England and Wales: the other is largely industrial and has a slightly larger proportion of people in the lower social classes.

In each town contact was made through general practitioners with a consecutive series of just over 700 newly pregnant women. Each woman was visited at the time of first reporting her pregnancy and at about the 36th week of pregnancy. The infants were visited by specially trained nurses at 10 days, at 6 weeks, and at 3, 6,9 and 12 months and thereafter at 6-monthly intervals until their fifth birthdays.

Immediately after the initial visit to the mother, an independent observer randomly allocated women into a 'supplemented' and a 'control' group. Women in the supplemented group were supplied, throughout their pregnancy and during any subsequent pregnancy, with milk tokens. At intervals after delivery, each was given tokens for her child until he or she reached age 5 years. Each mother was also given tokens for any other child under 5 years for whom she was responsible. 
The milk tokens were similar in appearance and in use to those which had been provided under the Welfare Food Act (1940). Each token was equivalent to the price of half a pint of milk, and arrangements for their acceptance were made with local milk delivery men.

An effect of the issue of milk tokens was anticipated at each of three levels - on milk purchases by the families, on the amount of milk drunk by the children, and on the growth of the children. Each of these effects was examined during the trial.

The records of milk delivery men were inspected, in confidence, and purchases by each family noted for a typical week in November each year. Unfortunately there were many firms, and records for only about half the families could be traced.

The amount of milk drunk or taken in puddings etc. by the children was estimated from answers to a questionnaire. To reduce bias such questions were buried within a host of questions on general dietary intake.

Measurements of growth were made by nurses who had been specially trained by one of us (DPD) and who were blind with regard to the receipt of tokens or not. At monthly intervals the 2 nurses in the two towns worked together and both measured a number of infants separately, and blind, in random order. Except for skinfold measurements, their results were consistently very close. Measurements at 5 years were made on all the children by one trained and highly experienced observer who was also blind with regard to group. Each child was seen within about 4 weeks of his fifth birthday, an equal number before and after the birthday.

The anthropometric methods used throughout were those described by Tanner et al. $^{3}$

Weight. Weight at delivery was obtained from hospital records. Weight at 5 years was measured on a beam balance.

Length. Crown to heel length was measured on a modified infant stadiometer. ${ }^{4}$ To give time for caputs to resolve, length was measured at 10 days, but for some infants this was exceeded, though seldom by more than a few days. Height at 5 years was measured on a stadiometer.

Head circumference. The maximum occipito-frontal measurement was taken with a disposable paper tape on the 10th day, or within a few days of this, and again at 5 years.

Skinfold thickness. Mid triceps skinfold was measured with Harpenden calipers at 10 days and again at 5 years.
Results of the study are presented here for the total $\bigcirc$ group as this was chosen to be representative of the $\overline{\frac{\partial}{2}}$. community. In an attempt to identify a subgroup which may be at greater than average risk of $\underset{?}{\overrightarrow{0}}$ nutritional deprivation, we then chose children in $\overrightarrow{0}$ families which, when the study child was aged $4 \frac{1}{2} \frac{C}{0}$ years, had an expenditure on food of under $£ 20$ per $\overline{\bar{\sigma}}$ week and 3 or more children, or an expenditure on $\mathbb{\Phi}$ food of under $£ 25$ per week and 4 or more children, or 5 or more children irrespective of money spent on $\mathrm{\omega}$ food.

\section{Results}

The number of pregnant women admitted to the trial, the number of infants born, and the number of $\%$ children seen at 5 years are shown in Table 1 . Losses were high, mainly due to removal out of the area. $\vec{\phi}$ Inspection of the data showed that losses were lower $\stackrel{\mathbb{W}}{-}$ in the children given tokens than in the 'control' children (about 14 and $21 \%$ respectively).

Table 2 examines any bias which might have been $\vec{z}$ introduced by these losses. The data suggest that the children lost to follow-up and their mothers and $\stackrel{\mathbb{D}}{\rightrightarrows}$ their families were very similar to those who remained $\frac{\partial}{8}$ in the trial until age 5 years.

Tables 3 and 4 examine the comparability betweeg $\overrightarrow{0}$ the token and control groups for the children who $\stackrel{\infty}{-}$ completed the study and were measured at 5 yearsis. Table 3 shows the comparability of the measure ments at birth, and Table 4 compares familial characteristics. These familial characteristics are those pertaining when the study child was aged 5

Table 1 Numbers of women contacted and the numbers lost at various stages to the trial in pregnant women

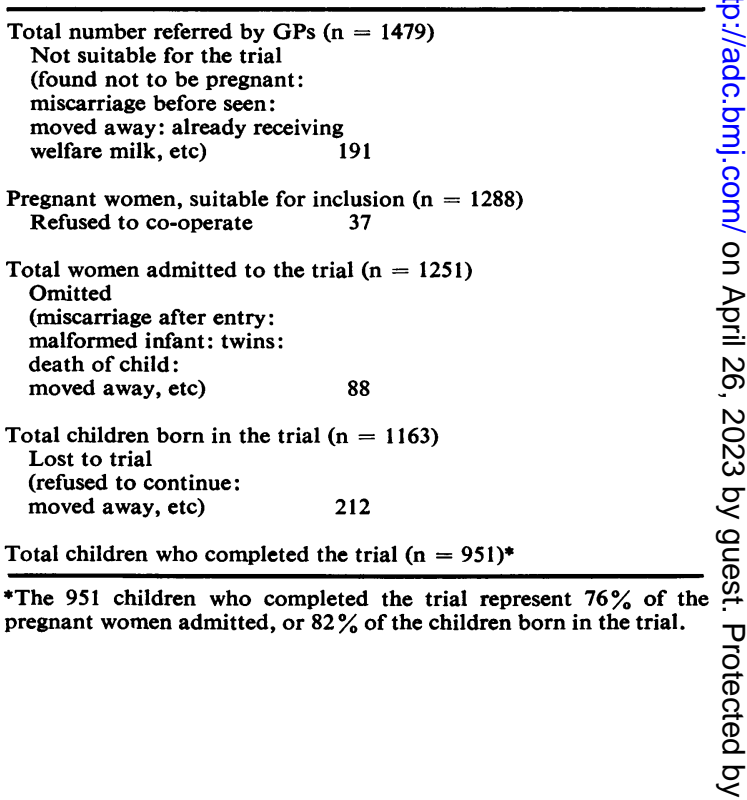


Table 2 Comparability of the children who completed the trial and were measured at age 5 years, and those who were lost to the trial between birth and age 5 years. Based on data collected during the pregnancies of the mothers (at 36 weeks) and on the children at birth, or at 10 days

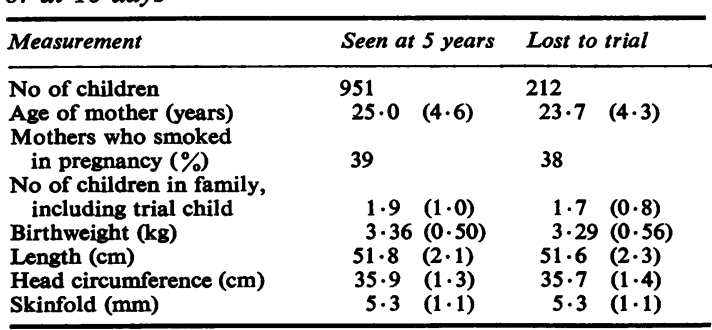

Data are percentages or mean (SD).

For the 1163 children, information is missing for the following: length $n=58$, head circumference $n=58$, skinfold $n=93$.

years. There is no evidence of any difference in any factor which might be important other than for smoking. Because of the known relevance of maternal smoking both to infant birthweight ${ }^{5}$ and growth in childhood ${ }^{6}$ we examined this difference in detail. Smoking habits had been obtained by questionnaire and answers had been grouped (zero, 1-4, $5-14,15-24$, and 25 or more cigarettes a day). Using mid points for these groupings and 30 for the highest group, an estimate of the mean daily cigarette

Table 3 Comparability of the children seen at 5 years. (Mean (SD) of birth measurements)

\begin{tabular}{lcccccc}
\hline Measurements & \multicolumn{3}{l}{ Boys } & & \multicolumn{2}{l}{ Girls } \\
\cline { 2 - 3 } \cline { 5 - 6 } & Tokens & Controls & & Tokens & Controls \\
\hline No of subjects & 276 & 237 & 234 & 204 \\
Weight (kg) & $3 \cdot 46$ & $3 \cdot 39$ & & $3 \cdot 32$ & $3 \cdot 24$ \\
& $(0 \cdot 49)$ & $(0 \cdot 50)$ & & $(0 \cdot 50)$ & $(0 \cdot 47$ \\
Length (cm) & $52 \cdot 4$ & $52 \cdot 3$ & & $51 \cdot 3$ & $51 \cdot 2$ \\
& $(2 \cdot 1)$ & $(2 \cdot 1)$ & & $(2 \cdot 0)$ & $(2 \cdot 1)$ \\
Head circumference (cm) & $36 \cdot 5$ & $36 \cdot 4$ & & $35 \cdot 4$ & $35 \cdot 4$ \\
& $(1 \cdot 3)$ & $(1 \cdot 2)$ & & $(1 \cdot 2)$ & $(1 \cdot 3)$ \\
Skinfold (mm) & $5 \cdot 4$ & $5 \cdot 2$ & & $5 \cdot 4$ & $5 \cdot 3$ \\
& $(1 \cdot 1)$ & $(1 \cdot 0)$ & & $(1 \cdot 0)$ & $(1 \cdot 1)$ \\
\hline
\end{tabular}

For the 951 children, information is missing for the following: length $n=40$, head circumference $n=41$, skinfold $n=67$.
Table 4 Comparability of the children seen at 5 years. Familial characteristics

\begin{tabular}{|c|c|c|c|c|}
\hline & \multicolumn{2}{|l|}{ Boys } & \multicolumn{2}{|l|}{ Girls } \\
\hline & Tokens & Controls & Tokens & Controls \\
\hline $\begin{array}{l}\text { Number of subjects } \\
\text { Age of mother (years) }\end{array}$ & $\begin{array}{l}276 \\
29 \cdot 8 \\
(4 \cdot 5)\end{array}$ & $\begin{array}{l}237 \\
29 \cdot 9 \\
(4 \cdot 5)\end{array}$ & $\begin{array}{l}234 \\
30 \cdot 8 \\
(5 \cdot 2)\end{array}$ & $\begin{array}{l}204 \\
29 \cdot 5 \\
(4 \cdot 1)\end{array}$ \\
\hline $\begin{array}{l}\text { Mothers who smoked } \\
\text { during pregnancy (\%) } \\
\text { No of children in family } \\
\text { Rank of study child }\end{array}$ & $\begin{array}{l}38 \\
2 \cdot 4 \\
(0 \cdot 9) \\
1 \cdot 9 \\
(1 \cdot 0)\end{array}$ & $\begin{array}{l}45 \\
2 \cdot 4 \\
(1 \cdot 0) \\
2 \cdot 0 \\
(1 \cdot 1)\end{array}$ & $\begin{array}{c}30 \\
2 \cdot 5 \\
(1 \cdot 1) \\
2 \cdot 0 \\
(1 \cdot 2)\end{array}$ & $\begin{array}{c}43 \\
2 \cdot 4 \\
(0 \cdot 9) \\
1 \cdot 9 \\
(1 \cdot 0)\end{array}$ \\
\hline $\begin{array}{l}\text { Social class: } \\
\text { I }+ \text { II (\%) } \\
\text { III }(\%) \\
\text { IV }+ \text { V ( } \%)\end{array}$ & $\begin{array}{l}23 \\
57 \\
20\end{array}$ & $\begin{array}{l}20 \\
63 \\
18\end{array}$ & $\begin{array}{l}18 \\
61 \\
20\end{array}$ & $\begin{array}{l}18 \\
59 \\
22\end{array}$ \\
\hline
\end{tabular}

Data are percentages or mean (SD).

For no item is information missing for more than 6 of all the 951 children except for social class which was unknown or unclassifiable for 136.

consumption was made. This was 5.4 in the 'tokens' group and 6.8 in the 'controls', a difference of about $1 \frac{1}{2}$ cigarettes a day. The relevance of this difference on growth is probably very small and it has been ignored in what follows.

It was our intention to examine the outcome of this trial at three levels, as described earlier. Data on milk purchases by the families (Table 5) indicate that the families who had received tokens purchased about 1.8 pints of milk a week more than the control families. Allowing for the number of children under 5 years in each family this excess could have been about $4 \frac{1}{2}$ pints a week, had the tokens been used entirely to supplement normal milk purchases.

Table 6 summarises data on milk drunk by the children at $4 \frac{1}{2}$ years. Again the receipt of tokens seems to have led to an excess but this was only about $2 \frac{1}{2}$ fluid ounces $(71 \mathrm{ml})$ per child a day.

Table 7 summarises the outcome of the trial in terms of the growth of the total groups of children. There is no evidence of any important difference between the children who received the tokens and those who did not. Indeed, the signs of the differences are, on the whole, inconsistent for the two genders.

There were 155 children in the 'vulnerable group'

Table 5 Milk purchases by households during the trial based on one week during November each year

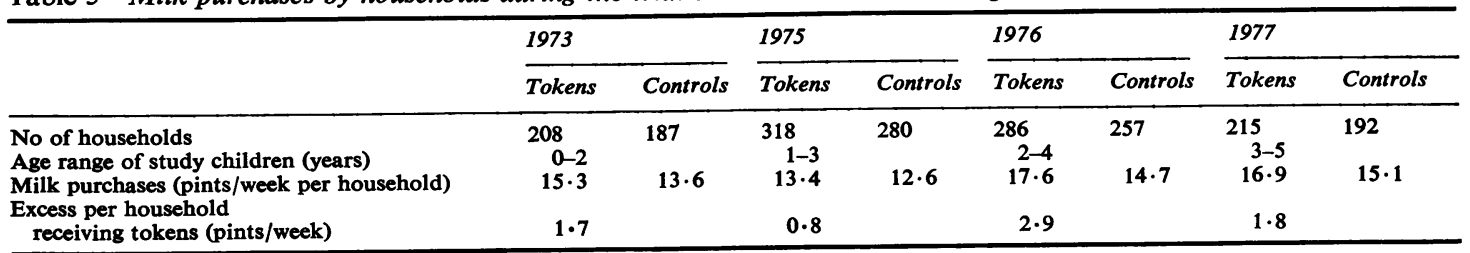

No comparable data available for November 1974. 
Table 6 Mean (SD) milk consumption by the children when aged $4 \frac{1}{2}$ years; based on answers by mothers to a general questionnaire on food consumption

\begin{tabular}{|c|c|c|c|c|}
\hline & \multicolumn{2}{|l|}{ Boys } & \multicolumn{2}{|l|}{ Girls } \\
\hline & Tokens & Controls & Tokens & Controls \\
\hline $\begin{array}{l}\text { No of subjects } \\
\text { Milk consumption }\end{array}$ & 273 & 232 & 230 & 199 \\
\hline (fluid ounce/day)* & $\begin{array}{l}20 \cdot 0 \\
(8 \cdot 1)\end{array}$ & $\begin{array}{l}17 \cdot 3 \\
(8 \cdot 2)\end{array}$ & $\begin{array}{l}17 \cdot 8 \\
(7 \cdot 9)\end{array}$ & $\begin{array}{l}16 \cdot 0 \\
(7 \cdot 1)\end{array}$ \\
\hline
\end{tabular}

$* 1$ fluid ounce $=28.4 \mathrm{ml}$.

Table 7 Outcome of trial in children at 5 years. Mean (SD) of growth measurements

\begin{tabular}{|c|c|c|c|c|}
\hline \multirow[t]{2}{*}{ Measurement } & \multicolumn{2}{|l|}{ Boys } & \multicolumn{2}{|l|}{ Girls } \\
\hline & Tokens & Controls & Tokens & Controls \\
\hline $\begin{array}{l}\text { No of subjects } \\
\text { Weight (kg) }\end{array}$ & $\begin{array}{c}276 \\
19 \cdot 0 \\
(2 \cdot 4)\end{array}$ & $\begin{array}{c}237 \\
19 \cdot 0 \\
(2 \cdot 6)\end{array}$ & $\begin{array}{c}234 \\
18 \cdot 7 \\
(2 \cdot 4)\end{array}$ & $\begin{array}{l}204 \\
18 \cdot 2 \\
(2 \cdot 4)\end{array}$ \\
\hline Height (cm) & $\begin{array}{r}108 \cdot 5 \\
(4 \cdot 1)\end{array}$ & $\begin{array}{r}108 \cdot 9 \\
(4.6)\end{array}$ & $\begin{array}{r}108 \cdot 2 \\
(4 \cdot 5)\end{array}$ & $\begin{array}{r}107 \cdot 7 \\
(4 \cdot 4)\end{array}$ \\
\hline Head circumference $(\mathrm{cm})$ & $\begin{array}{l}52 \cdot 2 \\
(1 \cdot 4)\end{array}$ & $\begin{array}{l}52 \cdot 4 \\
(1 \cdot 4)\end{array}$ & $\begin{array}{l}51 \cdot 3 \\
(1 \cdot 4)\end{array}$ & $\begin{array}{l}51 \cdot 2 \\
(1 \cdot 4)\end{array}$ \\
\hline Skinfold (mm) & $\begin{array}{c}7 \cdot 1 \\
(2 \cdot 2)\end{array}$ & $\begin{array}{c}7 \cdot 2 \\
(2 \cdot 4)\end{array}$ & $\begin{array}{c}7 \cdot 6 \\
(2 \cdot 3)\end{array}$ & $\begin{array}{c}7.6 \\
(2 \cdot 4)\end{array}$ \\
\hline
\end{tabular}

For the 951 children, information is missing for the following: weight $n=16$, height $n=6$, head circumference $n=43$, skinfold $n=74$.

Table 8 Outcome in children in the 'vulnerable group'. Mean (SD) of growth measurements

\begin{tabular}{|c|c|c|c|c|}
\hline \multirow[t]{2}{*}{ Measurement } & \multicolumn{2}{|l|}{ Boys } & \multicolumn{2}{|l|}{ Girls } \\
\hline & Tokens & Controls & Tokens & Controls \\
\hline $\begin{array}{l}\text { No of children } \\
\text { Weight (kg) }\end{array}$ & $\begin{array}{l}43 \\
18 \cdot 2 \\
(2 \cdot 3)\end{array}$ & $\begin{array}{l}35 \\
18 \cdot 6 \\
(2 \cdot 5)\end{array}$ & $\begin{array}{l}45 \\
18 \cdot 6 \\
(2 \cdot 4)\end{array}$ & $\begin{array}{l}32 \\
17 \cdot 8 \\
(2 \cdot 3)\end{array}$ \\
\hline Height (cm) & $\begin{array}{r}107 \cdot 2 \\
(4 \cdot 0)\end{array}$ & $\begin{array}{r}108 \cdot 2 \\
(4 \cdot 2)\end{array}$ & $\begin{array}{r}108 \cdot 0 \\
(4 \cdot 7)\end{array}$ & $\begin{array}{r}106 \cdot 6 \\
(3.4)\end{array}$ \\
\hline Head circumference $(\mathrm{cm})$ & $\begin{array}{l}51 \cdot 7 \\
(1 \cdot 2)\end{array}$ & $\begin{array}{l}51.9 \\
(1.6)\end{array}$ & $\begin{array}{l}51 \cdot 4 \\
(1 \cdot 5)\end{array}$ & $\begin{array}{l}51 \cdot 1 \\
(1 \cdot 0)\end{array}$ \\
\hline Skinfold (mm) & $\begin{array}{l}6 \cdot 8 \\
(2 \cdot 2)\end{array}$ & $\begin{array}{c}7 \cdot 1 \\
(2 \cdot 3)\end{array}$ & $\begin{array}{c}7 \cdot 6 \\
(2 \cdot 8)\end{array}$ & $\begin{array}{c}7.4 \\
(2 \cdot 0)\end{array}$ \\
\hline
\end{tabular}

For the 155 children, information is missing for the following: weight $n=2$, head circumference $n=11$, skinfold $n=13$.

defined by family size and expenditure on food as described earlier. Table 8 displays the outcome measurements in these children. Again there is no evidence of benefit from the receipt of tokens and again the signs of the differences between the groups are inconsistent in the two sexes.

\section{Discussion}

Early trials of the effect of a milk supplement on the growth of schoolchildren reported a beneficial effect. ${ }^{7-9}$ Another trial, run very recently in order to examine another aspect of the Welfare Food Act (1940) also detected an excess in growth of about $1.5 \mathrm{~mm}$ a year from a supplement of one-third of a pint of milk $(190 \mathrm{ml})$ given each school day to 7 - and 8-year-old children. ${ }^{10}$ It is generally believed that nutritional deprivation will have a more pronounced effect at younger rather than older ages and so a test of a supplement given during pregnancy and infancy was considered to be most valuable. The withdrawal of the Welfare Food Act (1940) made such a trial opportune.

However, the trial we report evaluated entitlement to a milk supplement, not the supplement itself. This is important, and while it gives only very limited and indirect evidence on a milk supplement and growth, yet it does give evidence of direct relevance to a national measure aimed to improve nutrition.

It is important to consider the effect of the entitlement by token at each of three levels.

There was an increase in milk purchases by the families who received tokens. Yet this increase was only about two-fifths of what the tokens provided. This in itself is an important finding of the trial, and is of direct relevance to any procedure similar to the issue of tokens, whether adopted as part of the national food policy, or on a smaller scale.

The effect on the amount of milk consumed was also small. Each token represented half a pin (10 fluid ounces) of milk and it was never expecte that children under age 5 years would consume alf that amount of extra milk. However, our finding, that about $2 \frac{1}{2}$ fluid ounces $(71 \mathrm{ml})$ extra a day was drunk when the children were aged $4 \frac{1}{2}$ years, was rather less than we had thought. A cupful of milk is about 4 to 6 fluid ounces and we had hoped that about this extra amount would have been taken daily by most of the children towards the end of the trial.

Whatever the effects on the other two levels, the absence of an effect on growth is of course the most important outcome of the trial and on this aspect our data are fairly conclusive.

The trial can be criticised however because the issue of tokens was delayed and each woman only received them, on average, for about half the duration of her pregnancy. Yet it is a fact that most women do not consult a doctor until pregnancy is well established, and so any nutritional provision, however it is made available, will suffer this limitation. In any case it is doubtful whether the milk drinking habits of adult women will be appreciably affected by the mere issue of tokens. The trial in the children was perhaps rather more realistic on both these aspects, in that the supplement was made available from birth, and their milk drinking pattern should have been more easily influenced. 
The criteria by which we defined a "vulnerable group' within our total population of children are of course open to question. There is no limit to the number of subgroups which could have been examined and the one we eventually decided on was chosen after very careful consideration. However it is important to remember, that, since the receipt of milk tokens had virtually no effect on growth in the total group of children, there just cannot be a subgroup of any size in which there was an appreciable beneficial effect, unless of course this was balanced by a deleterious effect of milk in another subgroup.

One aspect of this work which is of very great importance is the sensitivity of the trial, that is, the size of the differences in each outcome variate which would have been detected as statistically significant had it occurred. Table 9 displays estimates of differences in growth measurements from which the sensitivity of the trial can be judged. These data indicate that the trial was reasonably sensitive, that is, had the issue of tokens led to an excess in mean weight gain during the 5 years of $3 \%$ in all the children, or $6 \%$ in the 'vulnerable group' the results would have achieved statistical significance at $P<0.05$. Other estimates given in Table 9 indicate that the trial was very much more sensitive with respect to length and head circumference, and rather less sensitive for skinfold. In fact these estimates underestimate the probable sensitivity of the trial because they are based on one gender alone. If it is assumed that, had there been an effect, it would have been equal in the two genders and conclusions could therefore be based on all children combined, then the trial can be considered to have been about $40 \%$ more

Table 9 Least significant differences at $P \leqslant 0.05$ for the outcome growth measurements (based on boys only)

\begin{tabular}{llllll}
\hline Measurement & \multicolumn{2}{l}{ All children } & & \multicolumn{2}{l}{ 'Vulnerable group' } \\
\cline { 2 - 3 } \cline { 5 - 6 } & No & $(\%)$ & & No & $(\%)$ \\
\hline Weight (kg) & 0.4 & $(2 \cdot 3)$ & & 1.1 & $(5 \cdot 8)$ \\
Height (cm) & 0.8 & $(0 \cdot 7)$ & & 1.8 & $(1 \cdot 7)$ \\
Head circumference (cm) & 0.2 & $(0 \cdot 5)$ & & 0.6 & $(1 \cdot 2)$ \\
Skinfold (mm) & 0.4 & $(5 \cdot 6)$ & & 1.0 & $(14 \cdot 2)$ \\
\hline
\end{tabular}

Estimates given are $\boldsymbol{t} \mathbf{0 . 0 5} \times \mathrm{SE}$ difference. The figures in brackets indicate the proportion each estimate is of the mean measurement in the control children. sensitive than Table 9 suggests, and the data given in Table 9 can each be divided by about $1 \cdot 4$.

The overall conclusion of this work must therefore be that the trial, which was of reasonable sensitivity, gave no evidence consistent with a beneficial effect from the receipt of tokens entitling pregnant women and children under 5 years of age, to a pint of milk at half price each day.

We thank the families, officers of the Area Health Authorities, milk delivery men, nurses Carole Hopkinson, Daphne Williams, and Sylvia Roberts, Mrs Marion Jones, and the members of both our units who all gave constant support and encouragement.

\section{References}

1 Rona R J, Swan A V, Altman D G. Social factors and height of primary school children in England and Scotland. $J$ Epidemiol Community Health 1978; 32: 147-54.

2 Lindgren G. Height, weight, and menarche in Swedish urban school children in relation to socio-economic and regional factors. Ann Hum Biol 1976; 3: 501-28.

3 Tanner J M, Hiernaux J, Jarman S. Growth and physique studies. In: Weiner J S, Lourie J A, eds. Human biology: a guide to field methods. Oxford: Blackwell, 1969: 3-77.

4 Davies D P, Holding R E. Neonatometer: a new infant length measurer. Arch Dis Child 1972; 47: 938-40.

5 Davies D P, Gray O P, Ellwood P C, Abernethy M. Cigarette smoking in pregnancy: associations with maternal weight gain and fetal growth. Lancet 1976; i: 385-7.

6 Holsclaw D S, Topham A L. The effects of smoking on fetal, neonatal, and childhood development. Pediatr Ann 1978; 7: 105-36.

7 Auden G A. An experiment in the nutritive value of an extra milk ration. $J$ Roy Sanit Inst 1923; 44: 236-47.

8 McCollum E V. The nutritional value of milk. Proc World Dairy Congress 1924; 1 : 421-37.

9 Cory-Mann H C. Diets for boys during the school age. Medical Research Council Special Report Series No 105. London: HMSO, 1926: 1-81.

10 Baker I A, Elwood P C, Hughes J, Jones M, Moore F, Sweetnam $\mathbf{P}$ M. A randomised controlled trial of the effect of the provision of free school milk on the growth of children.J Epidemiol Community Health 1980; 34: 31-4.

Correspondence to Dr P C Elwood, MRC Epidemiology Unit (South Wales), 4 Richmond Road, Cardiff CF2 3AS.

Received 26 August 1980 